Kalpa Publications in Civil Engineering
Volume 1, 2017, Pages 30-36
$\begin{gathered}\text { ICRISET2017. International Conference on Re- } \\ \text { search and Innovations in Science, Engineering } \\ \text { \&Technology. Selected papers in Civil Engineering }\end{gathered}$

\title{
Finite Element Behaviour of RC Beam with Hybrid Arch Profile
}

\author{
Kedar N. Desai ${ }^{1}$, Mazhar A. Dhankot ${ }^{2}$ \\ PG Research Scholar, \\ ${ }^{1}$ Department of civil engineering Marwadi Education Foundation's Group of Institutions, Rajkot, \\ India \\ Associate Professor, \\ ${ }^{2}$ Department of civil engineering Marwadi Education Foundation's Group of Institutions, Rajkot, \\ India \\ kedardesai01@gmail.com, mazhar.dhankot@marwadieducation.edu.in
}

\begin{abstract}
A detailed study has been conducted for understanding the structural behaviour of a beam with Hybrid profile consisting of a concrete arch tied with steel reinforcement. The compression region generated due to flexural loading is converted into an arch which is connected by providing reinforcement at the bottom. The structural performance of this type of beam is not known yet owing to its complex shape and novelty. The main goal of the study is to examine the static behaviour of this beam under flexure and different support conditions comprising of simple support with and without horizontal restraint. Finite element analysis for the developed beam is conducted using standard FEA package. The results indicate that the strain at the level of steel in arch beam reduces by $31.8 \%$ with horizontal restraint whereas without horizontal restraint, there is an increase of strain by $50 \%$ as compared to beam having rectangular section with similar loading condition and flexural rigidity. The self-weight of the developed beam was reduced by $45 \%$ compared to conventional rectangular section. This study shows that the performance of the developed beam improves significantly if a suitable support conditions are provided.

Keywords: Hybrid arch profile, Arch beam, Finite element Analysis, Flexural Behaviour
\end{abstract}

C.D. Modhera, G.J. Joshi, D. Soni, I.N. Patel, A.K. Verma, L.B. Zala, S.D. Dhiman, D.R. Bhatt, J.M. Rathod, B.C. Goradiya, M.S. Holia and D.K. Patel (eds.), ICRISET2017 (Kalpa Publications in Civil Engineering, vol. 1), pp. 30-36 


\section{Introduction}

A precast concrete beam offers many advantages over in-situ casting. For example, greater control over the quality of materials and workmanship, cost efficiency (with standard forms continually reused) and improved health and safety (with casting carried out at ground level rather than at height) are all realized through the off-site production of structural beam. As a result, a lot of research work has been conducted into their design and performance. Concrete technology is continually develop gradually, as is the industry's knowledge of how to design and prophesy the behaviour of the resulting precast structural member (Toniolo 2012). Using such knowledge of design, the more efficient, cost-effective or flexible construction of precast beam can offer a key commercial benefit to a precast manufacturer.

It is identified that improved performance can be achieved through an on-going evaluation and questioning of existing design, manufacturing and construction practices. Thus this study aims to highlight any possibility for improved efficiency, identifying opportunities where it would be potential (and beneficial) to undertake or apply contemporary aspect, best practices for design process and construction process (M. N. KATAOKA 2012)

It could be seen prima facie that the scope of this study into the performance of precast concrete beam may be limited due to the maturity of the precast industry, particularly with regards to design and manufacturing methods. The overarching research aim, specifically focuses on improving the performance of precast concrete beam systems.

In the conventional rectangular beam load transfers like an arch analogy shown in figure-1.

Because of such load transferring pattern in conventional beam, an effort has been placed to develop a new type of beam profile that shall give a better structural efficiency. This study investigates the distribution of forces among the components of a relatively new beam with the hybrid arch profile. This beam has several advantages over traditional girders, including a lighter shipping weight and faster construction.

\section{Hybrid arch profile beam}

In conventional beam has a monolithic rectangular concrete section. In this new type of beam there is an arch provided in the beam at compression zone, under the arch section all the concrete is removed in the tension zone at the center of the beam. Two side blocks are provided either side of the beam, to resist the horizontal thrust generated in the arch (J. R. Hillman 2003). Tension reinforcement is provided at bottom side of the Beam to resist the tension force generated due to flexural action of the beam.

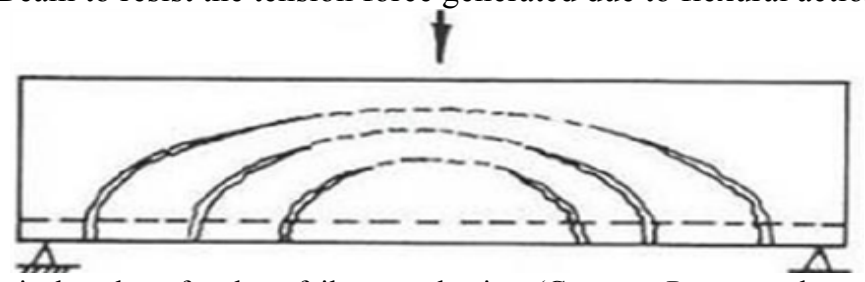

Figure 1:-Typical analogy for shear failure mechanism (Courtesy Prestressed concrete institute)

In this beam, a concrete arch tied at the bottom with steel reinforcement. The beams have a great advantage in that they are much lighter than similar sized concrete and steel beams (Ahsan 2012). This reduces transportation costs and facilitates movement of the beams at the construction site (John M. Civitillo 2014).

Different component of the beam:

- Compression reinforcement: The compression reinforcement consists of concrete poured into classical arch shape. 
- Tension reinforcement: The function of the tension reinforcement is to tie the concrete arch and contribute to the flexural stiffness of the Beam.

- Concrete web: The concrete web can be considered as a part of the compression reinforcement. Its main function is to transfer the loads from the lid to the concrete arch.

This research work is conducted to study the flexural behaviour of this new type of beam, load path in arch action and how load is distributed in tension reinforcement along with its load carrying capacity.

\section{Material Properties}

\subsection{Concrete}

Concrete has relatively high compressive strength, but significantly lower tensile strength, and as such is usually reinforced with materials that are strong in tension (often steel).

Maximum compressive strength of concrete was taken as $25 \mathrm{~N} / \mathrm{mm} 2$ and maximum tensile strength of concrete was taken $5 \mathrm{~N} / \mathrm{mm} 2$. Young's modulus was taken $23500 \mathrm{MPa}$ for the analysis and Poisson's ratio was taken 0.18 . The density of the concrete considered in the study was taken as $24 \mathrm{kN} / \mathrm{m} 3$

\subsection{Steel}

Steel is very good in resisting tensile force that's why steel is mainly used as tension reinforcement in the concrete structure. Density of the steel is taken as $7850 \mathrm{kN} / \mathrm{m} 3$ and young's modulus is $2 \mathrm{x} 105$ $\mathrm{MPa}$ and yield limit of tensile strength was taken $415 \mathrm{MPa}$.

\section{Modelling Of Beam With FEA Software}

Modelling of the developed beam is conducted in NX 10.0 software thereafter model file was converted into the *.step format and imported to ANSYS 15.0 software package. The model of the developed beam is shown in Fig.2 Maintaining the same mesh in each constituents of the beam guaranteed that the joints of any component coincide with the joints of other components that are in intimate contact with each other, consequently achieving the assumption of the perfect bond. Two equal point loads spaced at equal distance from left and right support was applied so that the behaviour of the beam can be assessed in pure bending condition without influence of shear. To understand the load flow of strain in concrete steel, loading was applied at an incremental rate of $10 \mathrm{kN}$ up to the design load obtained in rectangular section.

Moment $(\mathrm{Mu})$ carrying capacity of conventional beam having same size was carried out as per criteria mentioned in IS: 456-2000.

Considering the non-prismatic section of the beam, the sectional properties were calculated by dividing the entire beam into different sections viz. top arch flange, web and bottom flange. The neutral axis was located manually and moment of inertia at different section of the beam was calculated. The spherical curve, thickness of bottom and top flanges were decided in such a way that the compression zone of the entire beam lies within the arch. Thickness of top flanges is maintained constant throughout the beam length at $50 \mathrm{~mm}$. The curvature in the beam is generated for a strip having a width of $175 \mathrm{~mm}$, depth $100 \mathrm{~mm}$ and $3.80 \mathrm{~m}$ radius of curvature. A web having a constant thickness of $50 \mathrm{~mm}$ is provided between the arch and top flange. 


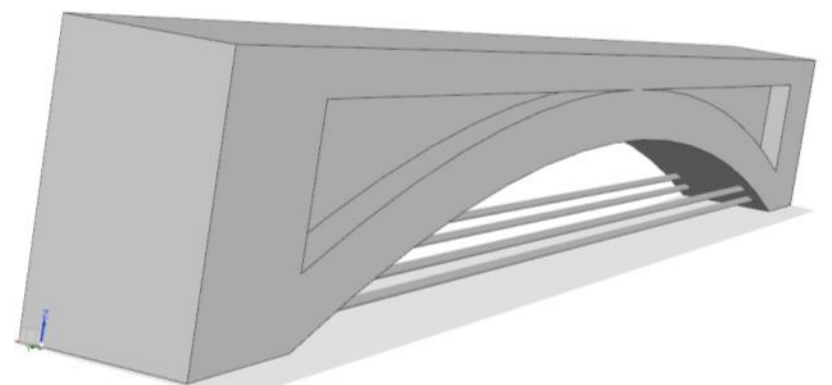

Figure 2 Typical beam with hybrid arch profile

\section{Result and Discussion}

Due to introduction of the arch profile, the center bottom part of the beam below the neutral axis was eliminated resulting in a large reduction in self-weight. Comparing the developed beam with conventional rectangular section, the self-weight of the developed beam reduces by $41 \%$ for given span and load carrying capacity.

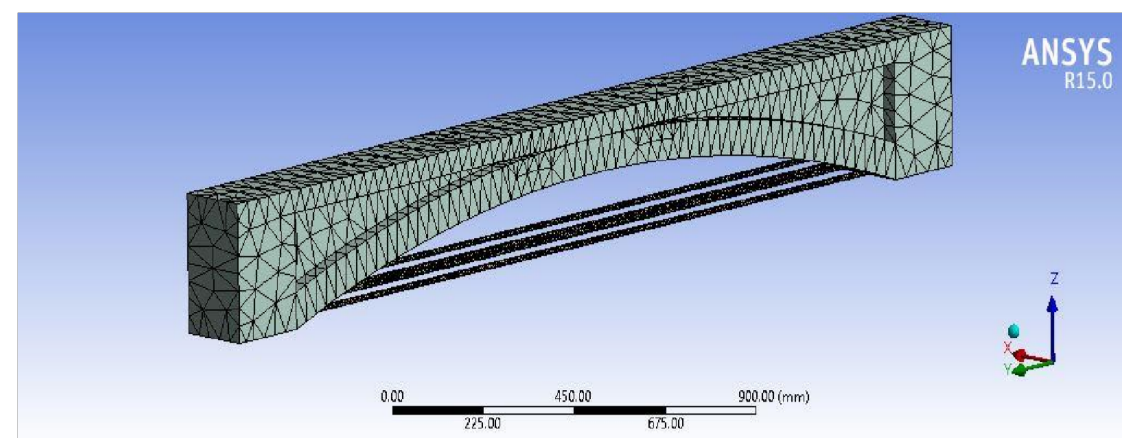

Figure 3 Generation of mashing in beam

The developed beam is highly suitable for precast members wherein the support condition plays an extremely important role for its effective performance. In the current study the developed beam is modelled and analyzed for simple support with and without horizontal restraint which encompasses the suitable support conditions on field. Parameters observed in the detailed FEA analysis are deformation and strains in various components of the developed beam. These parameters are evaluated for two point load conditions which could provide the pure flexural behaviour of the developed beam. The deformation of the arch profiled beam without horizontal restraint is shown in figure- 4 and figure- 5 . 


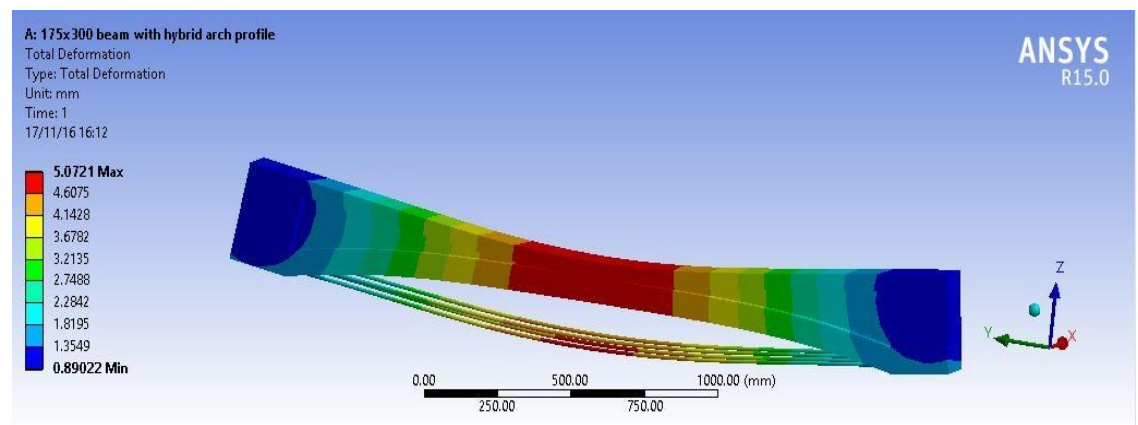

Figure 4 Deflection of simply support beam without horizontal restrain under two point design load

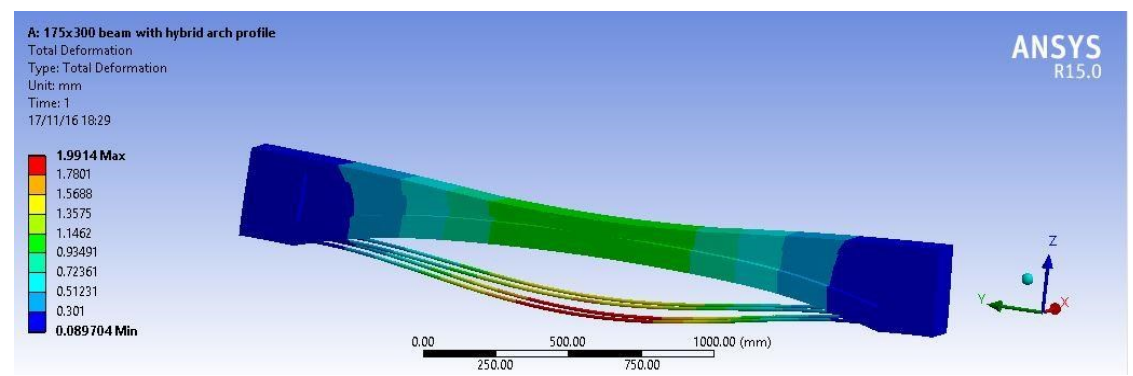

Figure 5 Deflection of the simple supported beam with horizontal restrain under two point design load

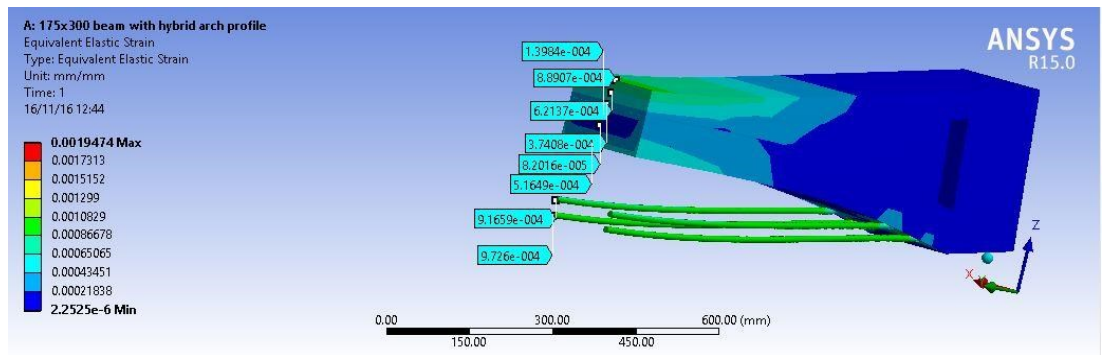

Figure 6 How to evaluate the strain profile for the new beam

Since there is no horizontal restraint provided, the arch action that generates a horizontal force that remains unchecked due to unavailability of the restraint in horizontal direction. This increases the deflection and with that the strain in each segment of the beam also increases. The strain profile across the depth of the beam at the center of the span is shown in figure-7(a). The strain in concrete and in Steel shows almost the same value depicting the elastic nature of the beam. To understand the flow of strain in steel and concrete arch, incremental load was applied on the beam and results were evaluated. The strain in concrete and steel at each load increment is shown in figure- 8(a) which shows that the strain in steel and concrete are almost same at each load increment which is analogous to the behaviour of a conventional rectangular section. The same arch beam was also modelled by providing horizontal restraint which resulted in a much improved performance as compared to the previous model without the horizontal restraint. The strain profile across the depth at the centre of span is shown in figure- 7(b). 

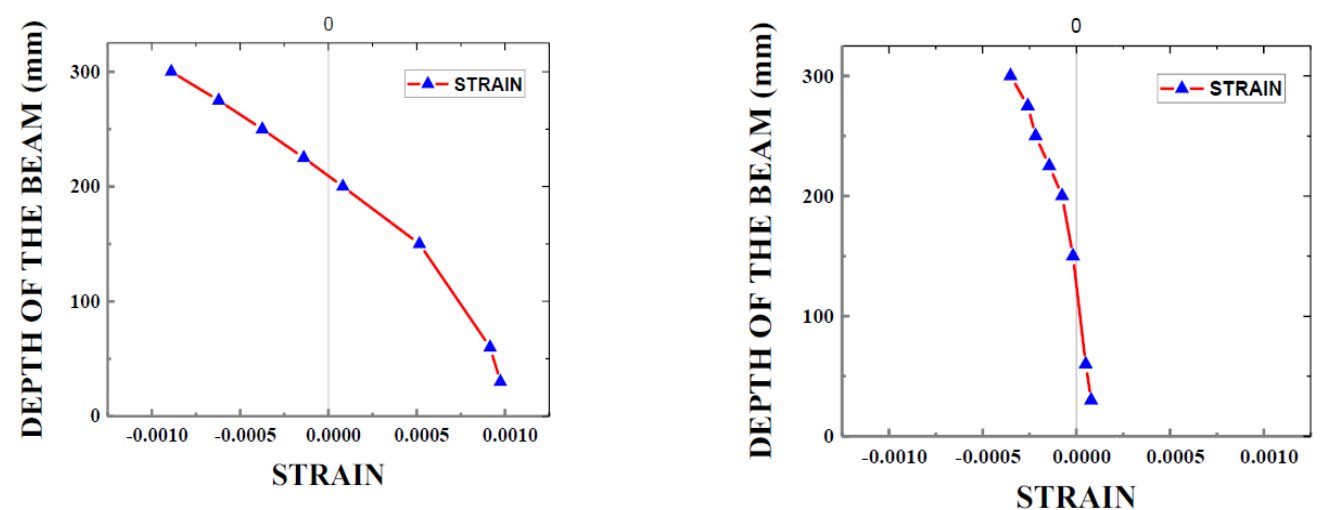

Figure 7 Strain profile of the newly develop beam (a) Without horizontal restrain (b) With horizontal restrain
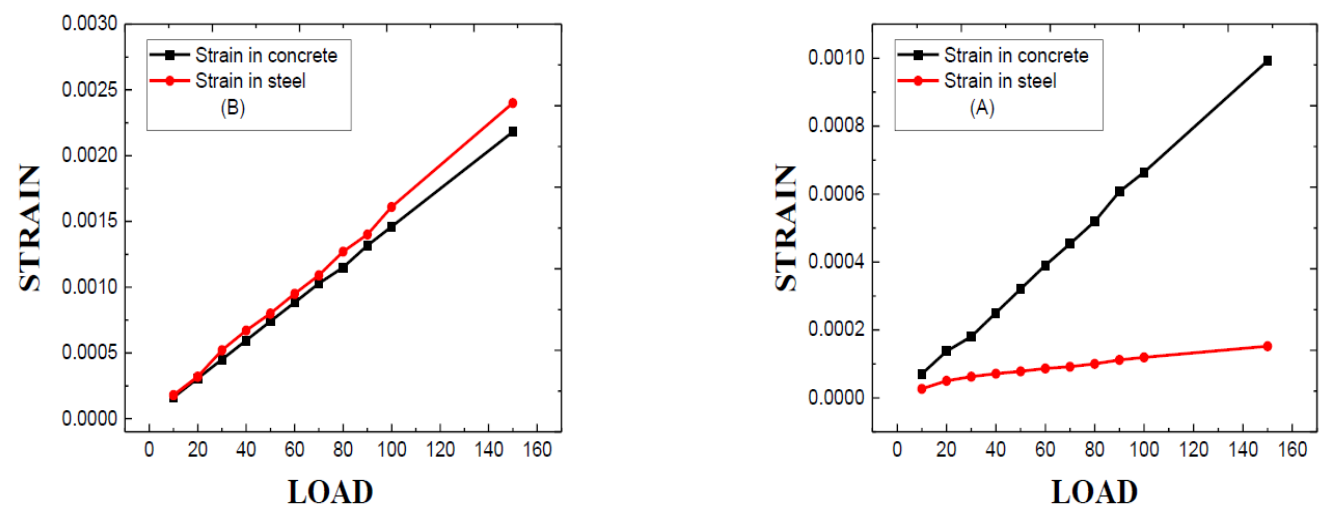

Figure 8 Strain in steel and concrete (a) without horizontal restrain (b) with horizontal restrain

The strain in at level steel reduced by almost $90 \%$ compared to beam without horizontal restraint however, the strain in concrete reduced by $55 \%$. The value of strain in the beam for incremental load is shown in figure-8 (b) that shows a significant difference in strains in concrete at top of the beam and at the level of steel provided at the bottom. The concrete arch action was quite significantly observed due to the horizontal restraint, which encountered for most of the load in arch through compressive stresses and hence the strain at the level of steel was reduced significantly. Both the arch profile beams were also compared with a conventional rectangular section having the same span, depth and width as developed arch profiled beam. The strain in beam without horizontal restraint exhibited an increase in strain up to $50 \%$ at the level of steel compared to conventional rectangular section. However, for the beam with horizontal restraint the strain value of strain reduced to $31.8 \%$ as compared to conventional rectangular section. This shows the highly improved performance of the arch beam in flexural loading condition if provided with a horizontal restraint.

Another parameter, which was evaluated in the above study, was deformation, which proves to be very important considering the serviceability aspect. The study shows that deflection is $41 \%$ higher in beam without horizontal restraint and $10 \%$ higher in the beam with horizontal restraint as compared to the conventional rectangular section. Figure-4 and figure- 5 shows the deflected shape of the developed beam without and with horizontal restraint. The increased deflection in the developed beam is owing to the reduction of depth at the center as compared to the conventional section. The flexural rigidity of the arch beam at the point, which has maximum bending moment, is lesser in case of arch profiled section compared to solid rectangular section. 


\section{Conclusion}

Precast structures is currently a developing industry which can provide high level of advantage compared to in-situ construction as far as quality and speed of construction are involved. To reduce the self-weight of precast beam, a hybrid arch profile beam has been developed and analytical model has been developed to understand its behaviour. Following conclusions can be derived from the finite element study of the arch profile beam.

1) Strain in arch profiled beam reduces by $31.8 \%$ at the level of steel as compared to conventional rectangular section when the arch beam is provided with suitable horizontal restraint.

2) Self-weight of the newly developed arch beam is observed to be reduces by $41 \%$ as compared to conventional rectangular beam with same dimensional properties.

3) If the arch beam is provided without horizontal restraint, the strain behaviour of the beam follows the conventional pattern. However, as compared to the conventional rectangular section the strain in concrete and steel increases by about $50 \%$ in arch beam.

The deflection in the developed arch beam with horizontal restraint is higher by about $10 \%$ when compared to conventional solid rectangular section. This is due to higher flexural rigidity of the solid section.

\section{References}

Aboelseoud M, Myers J. January 2015. "Finite-Element Modelling of Hybrid Composite Beam Bridge." Journal of bridge engineering.

Earley C. R, Abeol Seoud M. A, Myers J. J. une 2013. "Early-Age Behaviour and Construction Sequencing of Hybrid composite beam bridge Missori,USA." 11th international symposium on fibre reinforced polymer for reinforced concrete structure.

Hamahara M, Lida S, Uchida R, Suetsugu H. 2001. "Arch mechanism in reinforced concrete beams." 26th Conference on Our World in Concrete \& Structures. Singapore.

Harris D. K, Myers J, Gheitasi A. February 2016. "Performance and behaviour of hybrid composite beam bridge- Live load testing." Journal of Bridge Engineering, ASCE.

Harries D. K, Gheitasi A. june 2015. "Field testing and numerical modelling of hybrid composite beam bridge." 16th European bridge conference,. Edinburgh,UK.

Hillman, J. R. March 2003. Product application of hybrid composite beam system. Washington, DC: Transportation research board.

Kataoka M. N, Ferreira M. A. December 2012. "A study on the behaviour of beam-column connections in precast concrete structures: experimental analysis." IBRACON Structures and materials Journal.

Shainur, A. September 2012. Evaluation of HybridComposite Beam for Use in Tide Mill Bridge. Faculty of Virginia polytechnic institute.

Stephen V. N, Moen C. D, Cousins T. E,Roberts-Wollmann C. L. December 2013. "Experiments on a Hybrid-Composite Beam for Bridge Applications." Journal of the Transportation Research Board.

Kataoka M. N, Ferreira M. A. December 2012. "A study on the behaviour of beam-column connections in precast concrete structures: experimental analysis." IBRACON Structures and materials Journal.

Negro P, Toniolo G. 2012. Design Guidelines for Connections of Precast Structures under Seismic Actions. Joint Research centre of European commission. 